\title{
INOVASI HIJAB MENJADI LEBIH TRENDY DAN WUDHU FRIENDLY
}

\author{
Retno Hastuti \\ Program Studi Ekonomi Pembangunan \\ Universitas Pembangunan Nasional "Veteran" Yogyakarta \\ e-mail : retnohastuti77@gmail.com \\ Bella Febriantikaningrum \\ Program Studi Ekonomi Pembangunan \\ Universitas Pembangunan Nasional "Veteran" Yogyakarta \\ e-mail : febriatikabella@gmail.com \\ Septiana Pidya Nugraheni \\ Program Studi Ekonomi Pembangunan \\ Universitas Pembangunan Nasional "Veteran" Yogyakarta \\ e-mail : pidyanugraheni98@gmail.com \\ Erfa Saodah Rizqil Amin \\ Program Studi Ekonomi Pembangunan \\ Universitas Pembangunan Nasional "Veteran" Yogyakarta \\ e-mail : erfa00894@gmail.com \\ Nia Sarinastiti \\ Program Studi Ekonomi Pembangunan \\ Universitas Pembangunan Nasional "Veteran" Yogyakarta \\ e-mail : niasarinastiti7@gmail.com
}

\begin{abstract}
In the development of the hijab trend model in this modern era there are many different types of hijabs, just aurat, here we innovate the "Hi-Sunny" hijab with advantages not only as a cover for the genitals, in addition the connecting strap is wrapped in a suitable hijab Compilation ablution and re-available on the front of the headscarf that can be created more than 8 models of headscarves and pearl pearl tasel on both ends of the headscarf. In marketing, promotions are carried out online and offline. Online promotion is done using Instagram, Facebook, Whatsapp and other social media offline with ready kiosks. The purpose of this study was to create hijab clothing that was efficient, trendy and simple and added value to the function of the hijab.
\end{abstract}

\begin{abstract}
ABSTRAK
Dalam perkembangan model tren hijab di era modern ini banyak sekali berbagai model hijab yang bervariasi namun berfungsi sebatas penutup aurat saja, disini kami menginovasikan hijab "Hi-Sunny" dengan kelebihan tidak hanya sebagai penutup aurat saja dengan tambahan tali putus sambung dibagian dalam hijab yang mempermudah ketika berwudhu dan terdapat resleting dibagian depan hijab yang dapat dikreasikan lebih dari 8 model hijab serta terdapat tasel mutiara dikedua ujung hijab. Dalam pemasarannya dilakukan promosi secara online dan offline. Promosi online dilakuakan meggunakan Instagram, Facebook, Whatsapp dan media
\end{abstract}




\section{Buletin Ekonomi}

social lainnya sedangakan secara offline dengan membuka lapak. Tujuan penelitian ini adalah untuk menciptakan fashion hijab yang efisien, trendy dan simple serta menambahkan niali tambah dari fungsi hijab.

Kata Kunci : Hi-Sunny, hijab, promosi, trendy, fungsi, efisien

\section{PENDAHULUAN}

Indonesia merupakan salah satu negar adengan jumlah penduduk beragama Islam terbesar di dunia. Faktanya Indonesia termasuk dalam populasi muslim terbanyak didunia, kurang lebih diperkirakan ada 207 juta orang yang beragama Islam. Semakin kesini perkembangan agama Islam semakin banyak yang mana penduduk Islam khususnya kaum hawa menginginkan penampilan dengan gaya modis sesuai perkembangan zaman yang tidak melanggar ketentuan syariat Islam.

Salah satunya dengan mengikuti trend model hijab. Disini kita mengamati banyak kaum hawa ketika mengenakan hijab mengalami kesulitan saat berwudhu terutama ditempat terbuka, pastinya para kaum hawa enggan melepas seluruh hijabnya. Dengan perkembangan zaman banyak kaum hawa saat ini memilih mengenakan hijab yang trendi, modis dan tetap sesuai tuntutan agama tetapi masih belum banyak hijab yang dapat memenuhi keinginan para kaumhawa.

Untukitu kami menginovasikan Hijab "Hi-Sunny". "Hi-Sunny” ini memiliki kelebihan dari sisi desain dan model yang dilengkapi aksen tali putus sambung dibagian dalam hijab, resleting dibagian depan hijab, dan pernak-pernik tasel di kedua ujung bagian depan hijab. Hijab "Hi-Sunny" ini merupakan inovasi baru untuk mengatasi ketidak praktisan saat menggunakan hijab dan mempermudah saat berwundhu. Selain itu, hijab ini dapat dikreasikan menjadi 8 model hijab. Hijab yang kita buat diharapkan dapat menjadi salah satu hijab yang digemari para kaum hawa yang mengenakan hijab dikalangan mahasiswa maupun masyarakat umum.

Luaran yang kami harapkan dengan memproduksi "Hi-Sunny" ini adalah dapat meningkatkan keinginan masyarakat muslim dalam berhijab secara trendy dan mampu menghasilkan artikel ilmiah tentang peluang usaha dalam menginovasikan hijab menjadi lebih banyak model dengan satu hijab. 


\section{Buletin Ekonomi}

\section{METODE}

Pelaksanaan kegiatan PKM-K "Hi-Sunny" dilakukan dengan tahapan produksi yang pertama yaitu mendesain hijab. Berikut design "Hi-Sunny".

.Desain hijab tampak depan

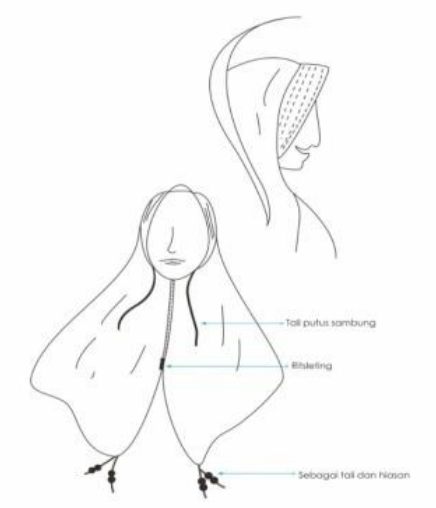

.Desain hijab saat berwudhu

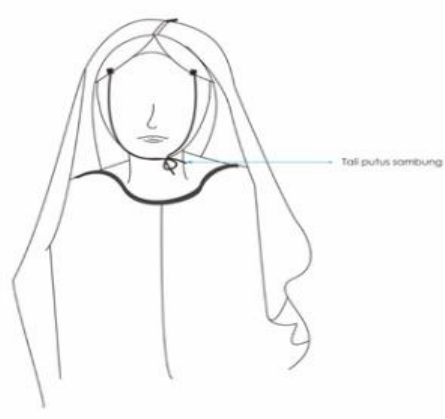

Selain itu, kita juga melakukan branding. Branding produk dilakukan dengan langkah pertama yaitu menentukan target pasar. Target pasar "Hi-Sunny" adalah wanita muslim di Indonesia. Berikut logo produk kami.

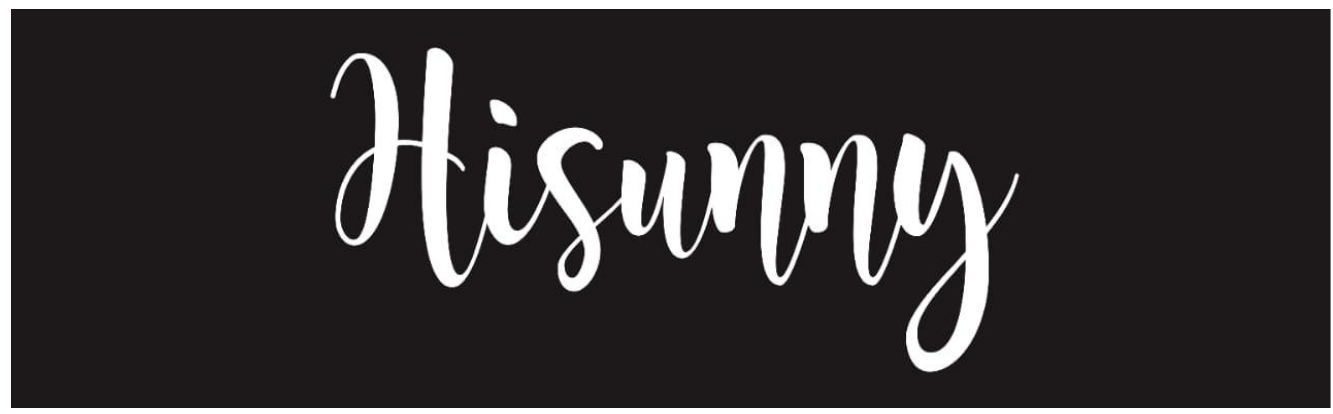

Setelah branding pelaksanaan kegiatan yang kita lakukan adalah strategi pemasaran dan tahap produksi. Kami melakukan strategi pemasaran secara online dan offline, yang dapat diakses dalam facebook, instagram, web, dan OA Line serta terdapat outlet di daerah Kulon Progo. Dan berikut tahapan produksi hijabnya. 


\section{Buletin Ekonomi}
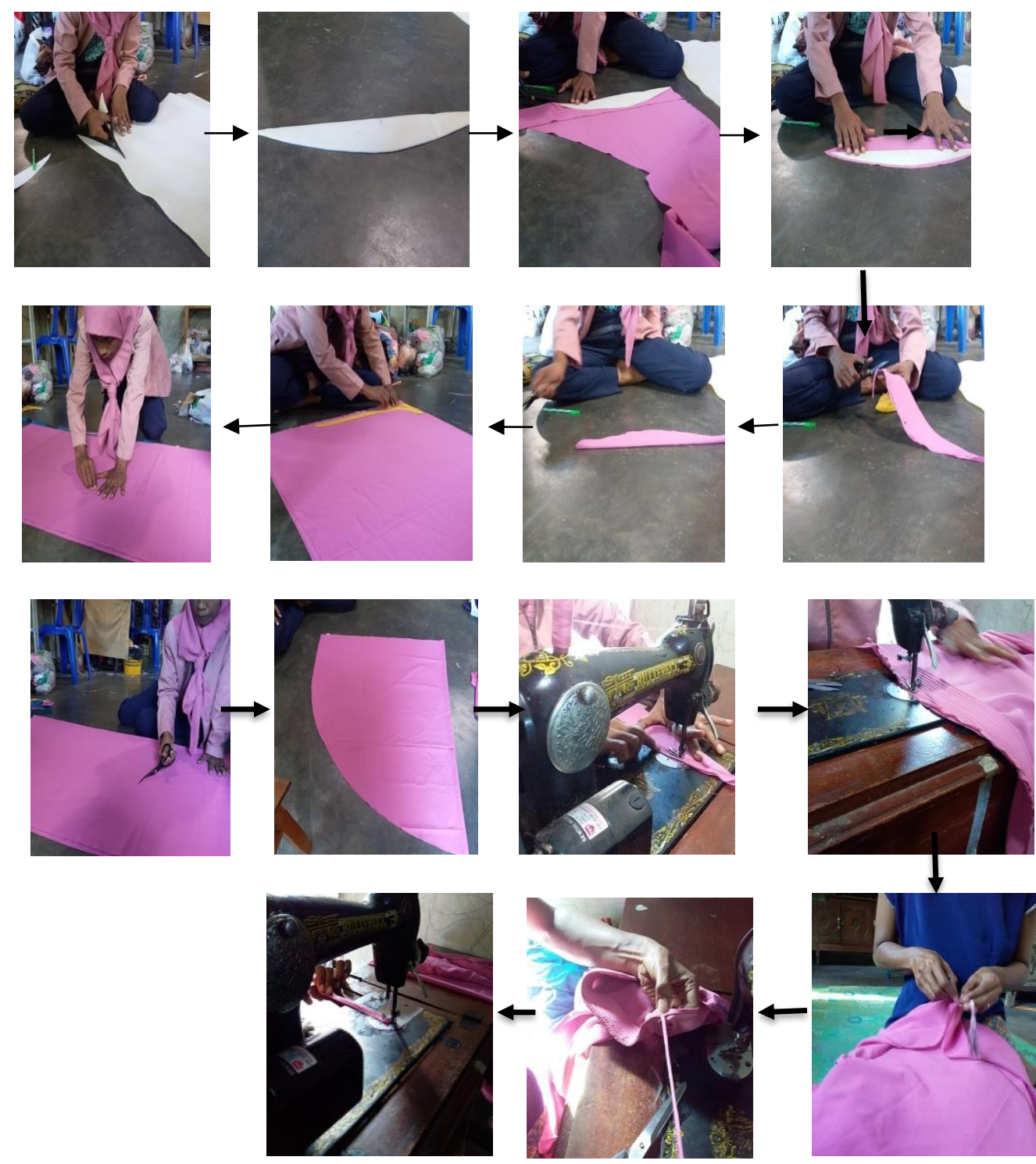

(Gambar di atas langkah pembuatan yang terdiri dari membuat pola pet kemudian pola hijab yang kemudian keduanya digabungkan dan setelah itu dipasang tali, resleting serta pernak-perniknya.).

Berikut hasil produksi dari kegiatan ini berupa hijab "Hi-Sunny", salah satu model dari ke 8 model hijab yang kita buat sebagai berikut : 

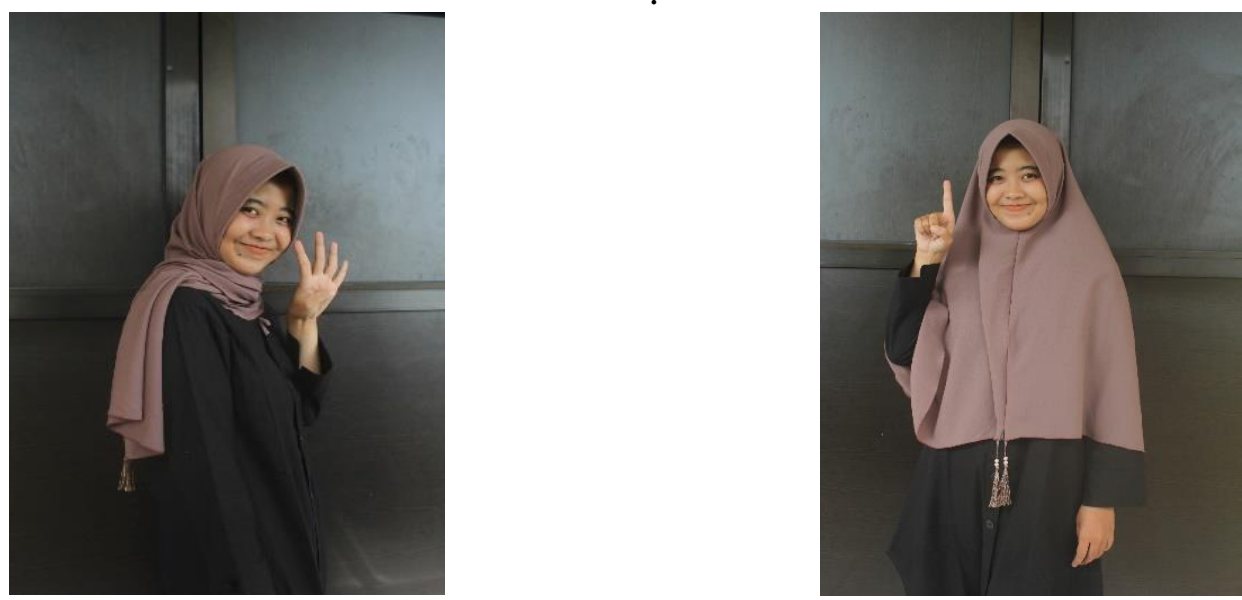

\section{ANALISIS DAN PEMBAHASAN}

Penjualan Hi-Sunny cukup membuat para kaum hawa tertarik dengan produk ini karena dirasa simpel, praktis kekinian dan mempermudah dalam berwudhu. Harga jual satuan HiSunny sebesar Rp 100.000,-. Penjualan mengalami kenaikan dan penurunan, penjualan terbanyak terjadi pada minggu ke 3 . Hal ini terjadi karena di minggu tersebut merupakan minggu ke 3 di bulan ramadhan yang mana mendekati hari Raya Idul Fitri.

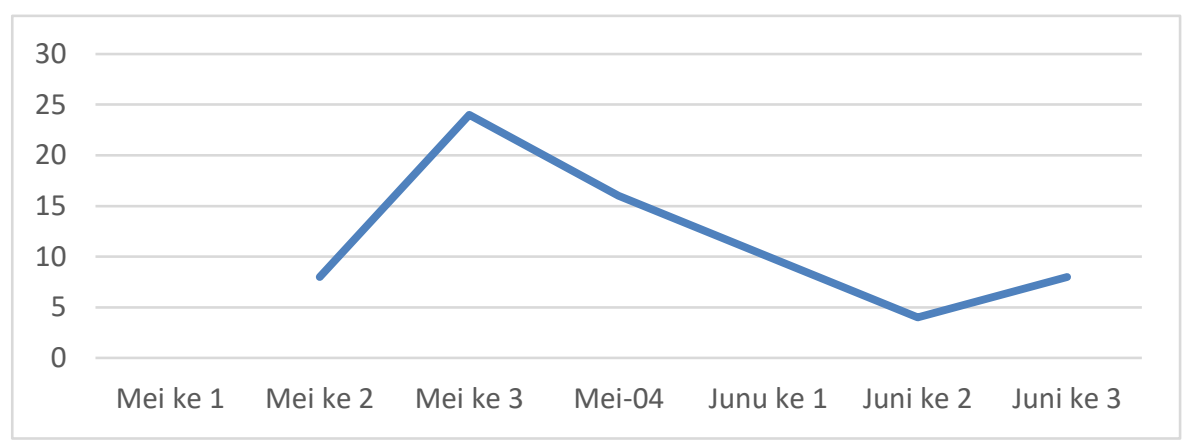

Ketercapaian Target Luaran dapat dilihat sebagai berikut :

Tabel 1. Tabel Target Luaran

\begin{tabular}{llll}
\hline \multirow{2}{*}{ No. } & \multirow{2}{*}{ Target } & \multicolumn{2}{c}{ Ketercapaian Target (100\%) } \\
& & SudahTercapai & BelumTercapai \\
\hline 1. & Survey Pasar & $100 \%$ & $0 \%$ \\
2. & PemenuhuanAlatdanBahan & $80 \%$ & $20 \%$ \\
3. & TempatProduksi & $100 \%$ & $0 \%$ \\
4. & PelaksanaanProduksi & $100 \%$ & $0 \%$ \\
5. Pemasaran & $80 \%$ & $20 \%$ \\
& a. Sosial Media (Instagram, Facebook,, & $60 \%$ & $40 \%$ \\
& $\quad$ dan WA ) & $70 \%$ & $30 \%$ \\
& b. Display Produk & $70 \%$ & $30 \%$ \\
6. Laporan & $82,5 \%$ & $17,5 \%$ \\
\hline
\end{tabular}

\section{KESIMPULAN DAN SARAN}

Kesimpulan 


\section{Buletin Ekonomi}

a. Inovasi hijab yang kita lakukan untuk mengatasi masalah wanita yang ingin tampil trendy tetapi tidak melanggar syariat Islam.

b. Hijab yang kita buat memiliki keunngulan yaitu dari sisi desain dan model yang dilengkapi aksen tali putus sambung dibagian dalam hijab, resleting dibagian depan hijab, dan pernak-pernik tasel di kedua ujung bagian depan hijab. Dan hijab yang

Saran dapat dikreasikan menjadi 8 model.

Masih diperlukan promosi yang lebih luas untuk mendapatkan pelanggan sebanyak mungkin dengan media online seperti instagram dan facebook.

\section{DAFTAR PUSTAKA}

Afwica Malisga, Mukhirah dan Fadhilah.2018.'Hijab Syar'i Multifungsi Bagi Remaja Muslimah"Vol 3(1):36-53

Arsita Desi dan Sri Rahayu.2010."Analisis Pengaruh Iklan, KepercayaanMerk, dan Citra Merek terhadap Minat Beli Konsumen”. Ekonomi dan Bisnis. Vol 13(1):37-45

https://rachmanfauziah.wordpress.com/tag/tata-cara-berwudhu-bagi-wanita-berjilbab-ditempat-umum/ diakses pada tanggal 7 November 2018 pukul 18.20 WIB

https://www.indonesia.investments.com/id/budaya/agama/islam/item248 diakses pada tanggal 5 November 2018 pukul 14.35 WIB

Narastika Rai dan Yasa Kerti."Peran Inovasi Produk dan Keunggulan Bersaing Memediasi Pengaruh Orientasi Pasar Terhadap Kinerja Pemasaran"

Rashin,Maraya Azizah dan Gina Astri.2018.”Identifikasi Inovasi dan Kinerja Bisnis dalam Meningkatkan Daya Saing.Penelitan Pendidikan”.

Suharsono,Riyanto Setiawan dan Sari,Rini Purnama.2019."Pengaruh Promosi Media Online terhadap Keputusan Pembelian Produk Hijab". Aplikasi Manajemen dan Inovasi Bisnis. Vol 1(2):2621-3230. 